\title{
Estructura social y conductas de saludo en dos especies de babuinos*
}

\section{Fernando Peláez del Hierro}

\author{
Universidad Autónoma de Madrid \\ Parque Zoológico de Madrid
}

La etología social ha sido un campo de estudio considerado experimentalmente como producto de las interacciones entre dos individuos. Incluso las relaciones establecidas dentro de sociedades tan desarrolladas como las de primates se describían como un conjunto de interacciones diádicas, de cuya síntesis se infería el sistema social completo (Kummer et al., 1974).

Esta visión, sin duda restrictiva, hay que buscarla en los antiguos conceptos de la etología, tal como evolucionó a partir de la segunda guerra mundial (p. e., Thorpe, 1979). Como consecuencia de una paulatina revisión han ido apareciendo gran número de publicaciones tendentes a dilucidar este problema. Uno de los campos de estudio más con- trovertidos ha sido el de la estructura social. La polémica, con una nueva dimensión, ha surgido dentro de la disyuntiva causal-funcional, en el intento de llegar a interpretar la estructura. La pregunta funcionalista llevaría a la búsqueda de los fines a los que sirve un modelo de estructura particular, es decir, a la afirmación de que las características de ese grupo son, en definitiva, producto de la selección natural y facilitan la supervivencia del mismo. Por el contrario, los causalistas se preguntan cómo los modelos de estructura existentes se encuentran consolidados en la actualidad, cómo los miembros del grupo crean y mantienen el sistema social en que viven.

Así, desde una perspectiva causal, se han considerado tres niveles de comple-

(*) Agradezco a los Dres. Terence R. Antboney (Dep. Zool. Univ. de Illinois), Irwin S. Bernstein (Dep. Psicol. Univ. Atlanta), Hans Kummer (Dep. Zool. Univ. Zurich) y Kazuyoshi Sugawara (Inst. Invest. Primatol. de Kyoto) sus críticas y comentarios a esta investigación. También quiero agradecer al Dr. Arsenio Fraile (Dep. Fisiol. Animal de la Fac. de C. Biol. de la Univ. Complutense de Madrid) su apoyo a pesar de las dificultades. Agradezco, por último, a Margarita Toral, las correcciones y sugerencias bechas al manuscrito y a Mariano Peláez las ilustraciones realizadas para este artículo. 
jidad: interacción, relación y estructura. Mientras que, en primer término, las interacciones vendrían determinadas por el repertorio conductual específico de la especie, las relaciones entre los individuos de un grupo serían la índole, cualidad y configuración de esas interacciones; la estructura, al más alto nivel, sería la índole, cualidad y. configuración de dichas relaciones. De esta forma, la estructura característica de cada grupo social vendría determinada por la norma de las relaciones entre sus miembros y éstas, a su vez, por la norma de las interacciones propia de los mismos. Tan sólo en los grupos más complejos cabría la posibilidad de que se diera la influencia inversa respecto al orden anterior (Hinde, 1975 y 1977). Aunque las relaciones entre los individuos se encuentren sometidas a continuos cambios temporales, «... la estabilidad de la estructura existe a pesar de los procesos dinámicos que hay dentro del grupo y, de hecho, depende de ellos» (Hinde, 1977, p. 327).

Este enfoque ha sido considerado como «internalista»e «interaccionista» por sus detractores (p.e., Crook, 1976). Crook, a lo largo de su bibliografía (ver Crook, 1970a, 1970b y 1976), abordando el tema desde una perspectiva funcional, defiende que la estructura social no es una forma concluida, sino que se encuentra en continuo reajuste: "los cambios históricos en una estructura social consisten en varios procesos laminados que están interaccionando con diferentes proporciones de operación... De forma que, mientras los efectos directos del ambiente pueden moldear la estructura rápidamente, los efectos indirectos de éste sobre las tradiciones aprendidas... y la selección genética, lo harán de manera más lenta» (Crook, 1970a, p. 198). Por otra parte, tampoco sería posible aplicar a la estructura social un papel semejante al de cualquier rasgo fisiológico, como han intentado hacer ver algunos autores, ya que la estructura aparece siempre como un sistema dinámico.

Para Gartlan (1973), las relaciones entre la estructura social y el hábitat dependerían tanto de factores filogenéticos como de factores ecológicos. Habría, por tanto, que hacer hincapié en las tendencias gregarias de los primates que les llevan, en forma general, a la creación de grupos, grupos que difieren en tamaño y composición dependiendo del género y especie. De cualquier manera, entre especies del mismo género e incluso dentro de la misma especie se observan variaciones de la estructura debidas, posiblemente, a condicionamientos ecológicos. Hasta el presente, concluye Gartlan,.no se han encontrado afinidades filogenéticas ni similaridades ecológicas que sirvan para predecir las formas básicas de la estructura del grupo, es decir, tamaño, composición sexual y tipo o frecuencia de las interacciones sociales.

La mayoría de los autores han coincidido en que los principales determinantes ecológicos que influyen en la estructura social son las fuentes de alimentación y la presión ejercida por los depredadores. Ambos constituyen factores limitantes ante los que las especies deben buscar estrategias óptimas que permitan a los adultos maximizar su contribución genética para las siguientes generaciones (Mason, 1976; Crook, 1976). Este sería, en definitiva, el sentido funcional de la estructura social y la explicación funcionalista de la misma.

Mason (1976) parece hacer el siguiente avance en el tratamiento de esta polémica, integrando parte de los argumentos hasta ahora vistos. Comienza afirmando que cada generación de animales construye su propia sociedad. Por tanto, hay que desechar la idea de que la organización social es fija y única y asumir que los grupos de primates no son sólo sistemas adaptativos, sino también sistemas adaptables, ya que esta adaptación al 
cambio se hace imprescindible en los escenarios naturales. Aparte de esta asunción funcional, hay que considerar que los grupos mantienen su cohesividad y continuidad a pesar de los cambios impuestos desde el exterior. Este mantenimiento del orden social se debe explicar mediante análisis causales, teniendo en cuenta tres niveles: el individual, donde el sujeto con su repertorio de conductas sociales e influido por la experiencia, es una unidad competente capaz de contribuir al cuerpo social. El individuo es activo modificador y resulta modificado por las relaciones sociales. Las aptitudes cognitivas de los primates juegan un importante papel en la regulación de la vida social, quizá de forma más determinante que en cualquier otro caso de animal gregario, «... ya que los primates poseen excelentes memorias, son capaces de formar conceptos, responden a relaciones abstractas y desarrollan hipótesis y estrategias». Un segundo nivel, el Social, incluiría las relaciones entre los miembros del grupo con sus respectivos repertorios categorizados en clases de edad, sexo, etcétera. El tercer nivel estaría referido al entorno del sistema social, que incluye las características del hábitat con algún tipo de influencia sobre el conjunto del grupo.

Aunque Mason suscita esta visión de síntesis, deja claras sus preferencias al concluir que «... la cuestión es que las formas distintivas e inusuales en la evolución de la vida social de los primates, son menos probables en la estructura del sistema social que en los procesos y dinámicas que las producen; éstas dependerían, en último lugar, de las características fisiológicas de los individuos» (Mason, 1976, p. 450).

El objeto de este trabajo sería buscar una relación entre una categoría de conducta (movimientos de saludo) y las estructuras sociales características de las dos especies estudiadas pertenecientes al género Papio. Los movimientos de saludo se definieron como «pautas motoras, ritualizadas, con la existencia de patrones cohesivos $\mathrm{y}$ tendentes a comunicar un estado entre el actor y el receptor que evitara posibles interpretaciones maladaptativas, en orden al mantenimiento del código social» (Peláez, 1982). Aunque se discutirá más detalladamente en las siguientes secciones, como resultado de los estudios comenzados en 1975 en el parque zoológico de la Casa de Campo de Madrid, se describieron seis maniobras de salutación (ver Material y Método), realizadas entre los machos adultos de una colonia mixta de babuinos (Papio). Estas maniobras aparecían como específicas de las especies, dadas las diferencias que se encontraron en la ejecución de los movimientos (Peláez, 1982). Efectivamente, de las dos especies estudiadas, el papión sagrado ( $P$. bamadryas) era capaz de realizar los seis tipos de saludo. Por el contrario, los papiones amarillos $(P$. cynocepbalus) poseían un repertorio limitado a la ejecución de sólo tres de los saludos que se describieron (ver Material y Método). Pero no solamente aparecían diferencias cuantitativas respecto al número de maniobras del repertorio de cada especie, sino que existían diferencias cualitativas entre los tres movimientos exclusivos de papión sagrado y los otros tres realizados por todos los machos. Esta segunda diferencia consistía en un mayor refinamiento de los saludos exclusivos de hamadríade, sin contacto físico y simétricamente llevados a cabo por ambos participantes. Para el resto de los movimientos, el contacto y la asimetría era la norma en su realización.

Dado que ambas especies poseen estructuras sociales diferentes y dado que el macho híbrido ( $P$. bamadryas $X P$. $c y$ nocepbalus), poseedor de la misma estructura social del papión sagrado, tiene también el mismo repertorio de saludos que éste, era lógico pensar en una posible 
relación movimientos de saludo-estructura social. La intención de este trabajo sería, por tanto, dar una visión más amplia de las maniobras de salutación que la considerada en la anterior definición: los movimientos no serían maniobras con la función exclusiva de evitar los daños (en general) de la agresión intraespecífi$\mathrm{ca}$, sino que, con esta base, poseerían distintas funciones (no fácilmente determinables) relacionadas con el tipo de estructura social y los niveles que consideremos en ella.

\section{MATERIAL Y METODO}

La colonia de babuinos se encuentra situada en una instalación de grandes dimensiones pertenecientes al parque zoológico de la Casa de Campo de Madrid. Se formó en el año 1974 con la adición de trece nuevos individuos a los trece ya existentes, que provenían del antiguo parque zoológico del Retiro. Partiendo de estos 26 animales, en la actualidad se cuenta con un grupo de 72 , categorizados por edades y sexo de la siguiente forma: 30 adultos $(2$ machos y 28 hembras), 15 subadultos ( 5 hembras y $10 \mathrm{ma}$ chos) y 20 jóvenes (algunos todavía lactantes). Al comienzo del año 1975, la colonia estaba compuesta por 44 individuos, incluidos 4 machos adultos y $8 \mathrm{ma}$ chos jóvenes (Peláez, 1982). En el presente se está realizando un estudio longitudinal con la observación de 22 machos (adultos, subadultos y jóvenes).

Tanto el macho hamadríade (Papio bamadryas) como el híbrido (1) ( $P$. bamadryas $\times P$. cynocephalus) poseen su propio harén, compuesto de machos y hembras de distintas edades, tal como corresponde a la estructura social típica de hamadríade (p. e., Kummer, 1968a y 1968b; Anthoney, 1975) (Cuadro 1). Por el contrario, los dos machos cinocéfalos (P. cynocephalus) formaban pare- jas inestables con el resto de las hembras adultas durante los períodos de receptividad sexual. Estas hembras se consideraban como periféricas por no pertenecer a ninguno de los harenes mencionados.

El método de observación consistió en la anotación de todos los movimientos de saludo entre los cuatro machos (dos a dos) considerados a la vez en cada una de las sesiones de observación ( $« \mathrm{Sam}$ pling all occurrences of some behaviors» en Altmann, 1974). Los distintos tipos de movimiento se anotaron mediante nominaciones y signos ilustrativos de la maniobra en cuestión. También se obtuvieron fotografías con material de $35 \mathrm{~mm}$ y película Super-8 de las diferentes pautas motoras. Como resultado se describieron seis movimientos de saludo: $\mathrm{Cir}$ cular (Fig. 1), Semicircular (2), Cara a cara (Fig. 2) (exclusivamente realizados por hamadríade e híbrido (Cuadro 2)), Presentación de grupa (Fig. 3), Tirón de pene (Fig. 4) y Monta (Figs. 5 y 6) (realizados por todos los machos (Cuadro 2)). Se consideraron saludos inconclusos aquellos que, una vez iniciada la maniobra por uno de los machos, no obtenían respuesta por parte del potencial receptor (Peláez, 1982).

\section{DISCUSION}

Los movimientos ritualizados juegan el papel de sistemas de comunicación tendentes a conseguir una interpretación óptima, sin ambigüedades, por parte del receptor ante la señal del emisor. Para obtener este óptimo de interpretación necesaria que evite respuestas maladaptativas, son precisos códigos de señales establecidos entre los participantes $e$, incluso, por el conjunto social al que pertenecen, que necesita conocer el resultado de esas interacciones por sus efectos directos o indirectos sobre dicho conjunto. Para la consecución de estas «señales 
CUADRO 1

Comparación de distintas características en la organización social de: babuinos sagrados ( $\mathrm{P}$. hamadryas) y babuinos de sabana ( $\mathrm{P}$. cynocephalụs, $\mathrm{P}$. anubis). Según diversos autores

\begin{tabular}{lll}
\hline $\begin{array}{c}\text { Caracterís- } \\
\text { ticas }\end{array}$ & Babuino sagrado & Babuinos de sabana \\
\hline
\end{tabular}

Ecología

Relaciones de dominancia

Reproducción

T a maño $y$ composición de los grupos

Unidad básica de organización

Reproduccion

Vínculos macho-hembra

Defensa

Saludos
Regiones áridas y semiáridas, incluso desérticas o con predominio de la estación seca.

Descanso en acantilados rocosos (p. e., Kummer, 1968a; Crook, 1970).

Tropas con hasta 350 indiv. (Kummer, 1968a). De hasta 750 indiv. (Kummer, 1968b). $X$ de 354 indiv. en Jolly (1972).

Unidad único-macho-líder formada por el macho alfa, hembras y jóvenes constituyendo el harén. Varias unidades forman la tropa. Todas las unidades se reúnen en las «rocas de dormir» (p. e., Kummer, 1968a y b; Hall, 1968; Hall y DeVore, 1965; Nagel, 1971 y 1973).

El macho alfa domina exclusivamente en su harén (Hall, 1968; Kummer, 1968a). Las distintas unidades se toleran, conservando distancias en las zonas de dormir (Kummer, 1968a y b).

Los machos alfa copulan sólo con hembras de su unidad (Kummer, 1968b). Deme coincide con harén (Wilson, 1980; Altmann y Altmann, 1970).

Las hembras siguen al macho-lider que las mantiene unidas a él mediante conducta de pastoreo (Herding behaviour), incluso con agresión. Hembras muy atentas al macho líder (Chance, 1967). Subunidades familiares estables.

Cada macho-líder defiende su unidad. En conflictos graves, los líderes de distintas unidades se juntan (Kummer, 1968a).

Circular, Semicircular, Cara a cara, Presentación, Monta y Tirón de pene (Peláez, 1982).
Sabana boscosa hasta sabana abierta. También regiones semiáridas. Descanso en árboles (Jolly, 1972; Gartlan, 1973).

Grupos de 10-100 indiv. (Nagel, 1973) $y$ de 40-80 en Kummer (1968b) $X$ de 80 en cinocéfalos y de 40 en anubis (Jolly, 1972).

Grupos multimacho (Nagel, 1971). Fácil intercambio de machos entre los grupos (Cohen, 1969).

Dominancia lineal entre todos los machos del grupo (Hall, 1968). Mucha tolerancia en las distancias entre machos (Nagel, 1971). La tolerancia depende de la ecología concreta (Hall, 1968).

El macho alfa copula con cualquier (¿?) hembra en celo. El deme es el grupo. Las relaciones de dominancia varían dependiendo de la existencia de hembras en celo (Hausfater, 1975).

Vínculo temporal ( $¿$ ?) con hembras en celo. No subunidades familiares estables. Los machos siguen a las hembras en celo (p. e., Nagel, 1971).

El macho alfa ataca y es seguido por los otros machos.

Presentación, Monta y Tirón de pene (v. texto). 


\section{CUADRO 2}

Movimientos de saludo realizados por los cuatro machos adultos de la colonia (1)

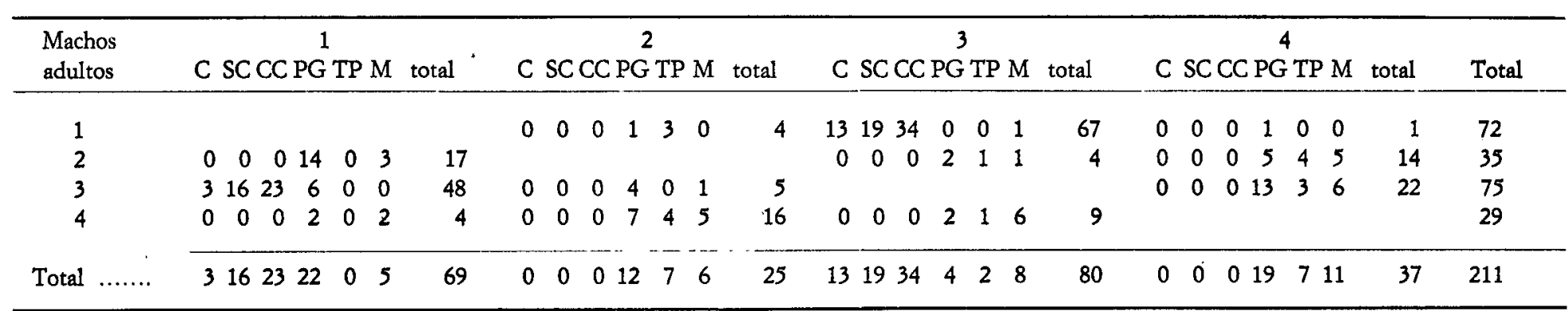

1: Hamadriade; 2: Cinocéfalo; 3: Híbrido; 4: Cinocéfalo.

C: Círculo; SC: Semicirculo; CC: Cara a cara; PG: Presentación de grupa; TP: Tirón de pene; M: Monta.

(1) Cuadro tomado de Peláez (1982), Primates. 


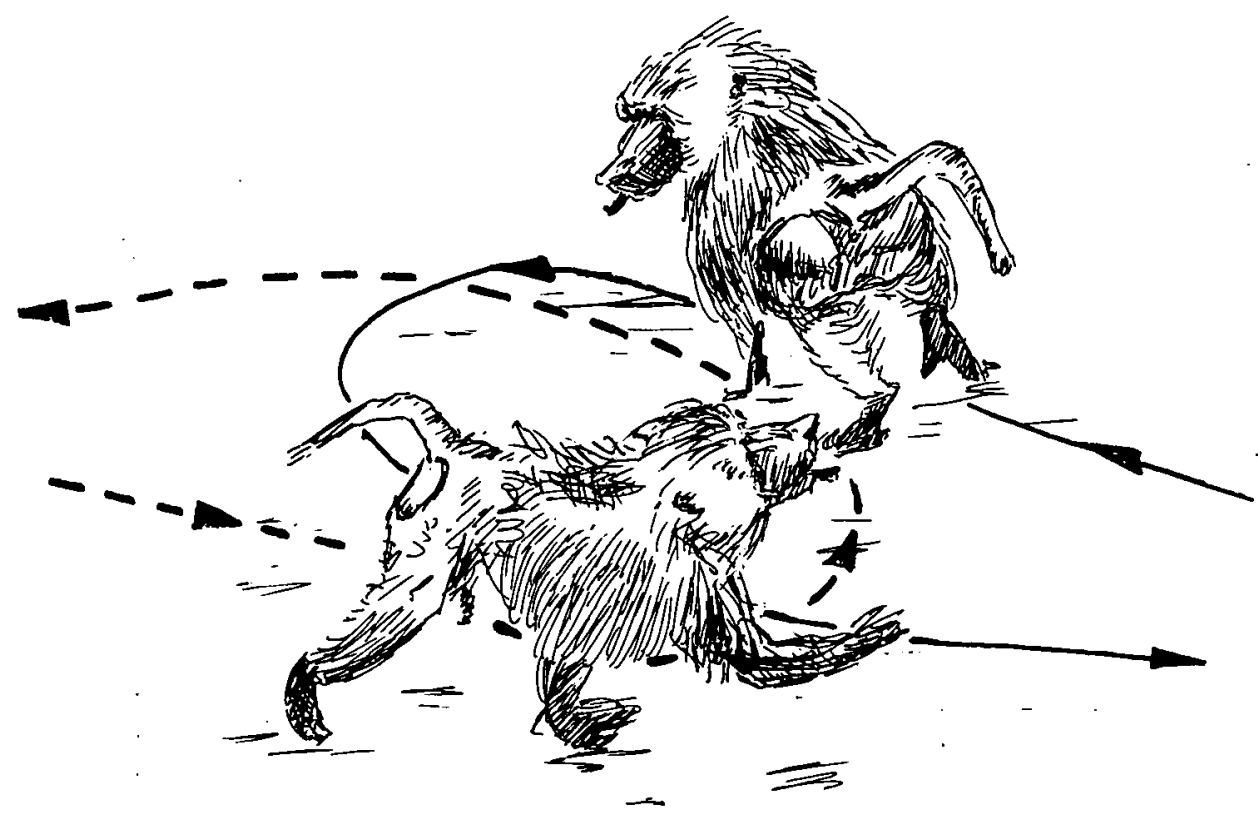

Fig. 1. Los dos machos, que se aproximan desde direcciones opuestas, giran $360^{\circ}$ el uno en torno del otro. La salida del movimiento se da en la misma dirección de la que venía cada uno

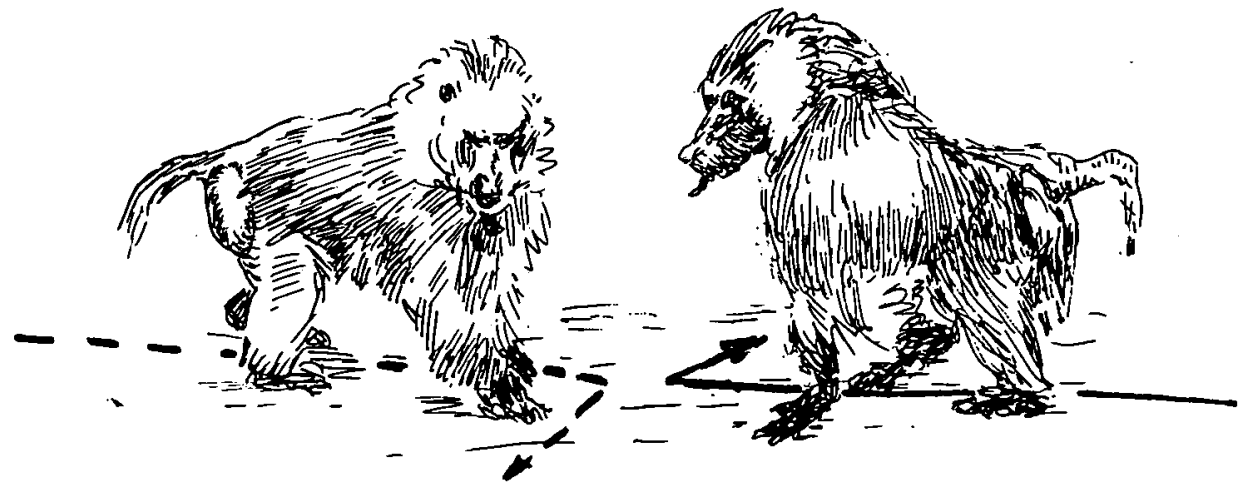

Fig. 2. Ambos macbos se aproximan tensamente viniendo de direcciones opuestas. Se mantienen un instante enfrentados y se separan rápidamente en la misma dirección de la que cada uno venía 


\section{Estudios}

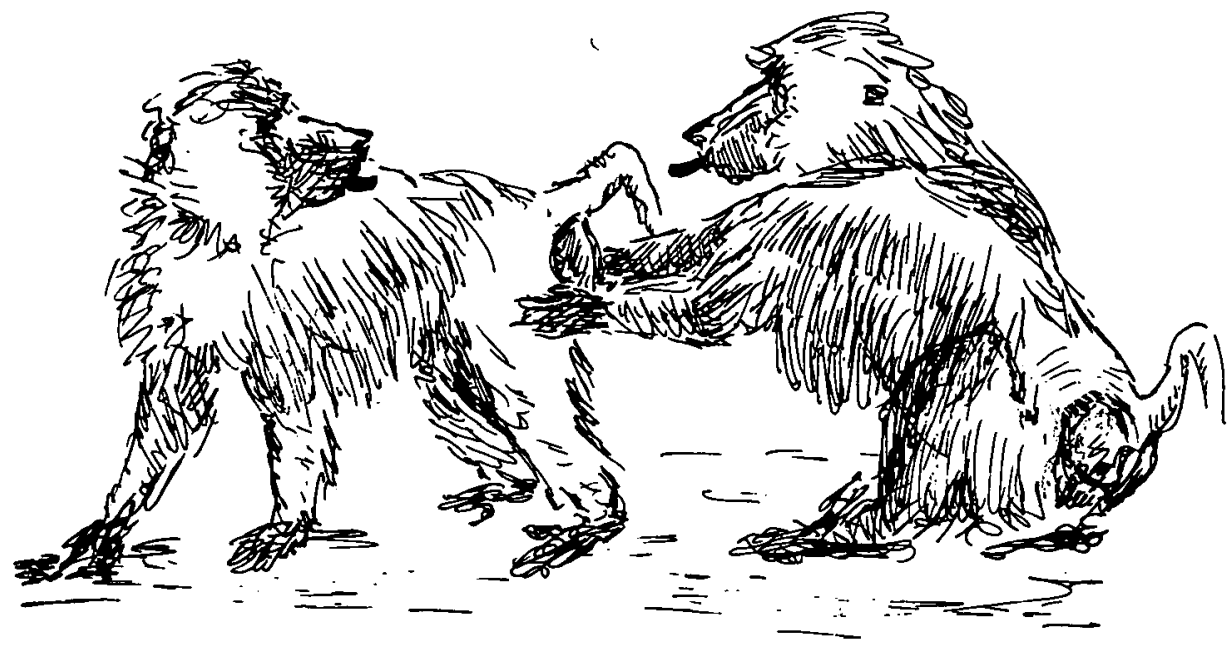

Fig. 3. Uno de los machos se aproxima al otro que permanecía estático. El primero presenta su grupa que es tocada por el segundo. Al mismo tiempo se producen intercambios cobesivos

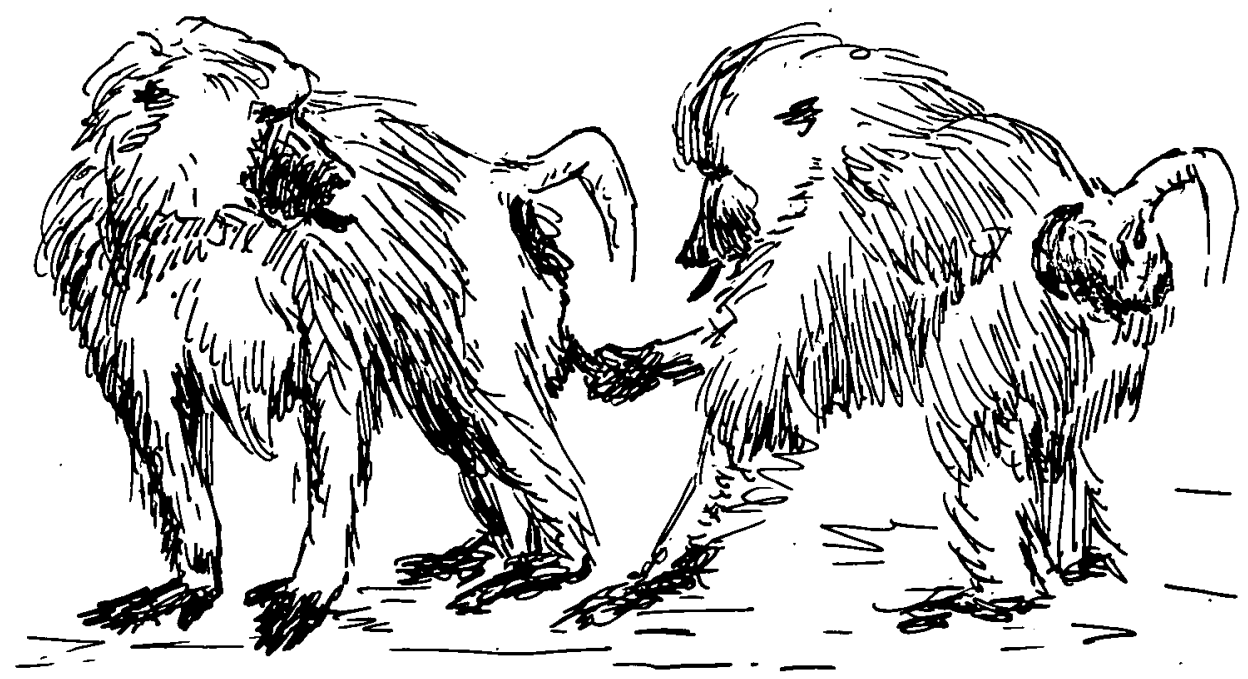

Fig. 4. Una vez que se ba producido la aproximación entre los machos, uno de ellos palpa los genitales del otro. La palpación puede ser mutua y no necesariamente con una anterior presentación 


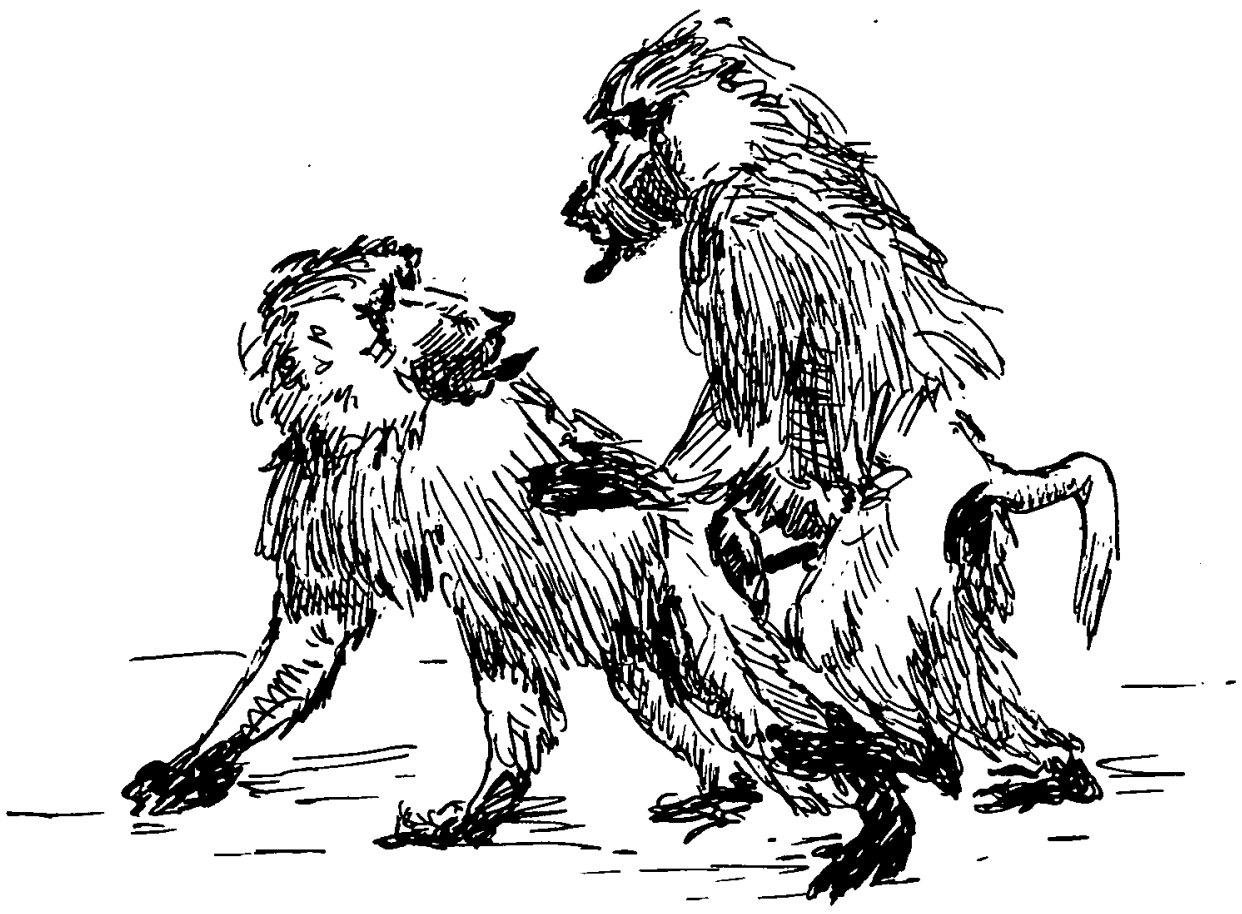

Fig. 5. En ocasiones, el macbo receptor de la presentación monta al que se presenta. Para ello sube sobre sus tobillos al mismo tiempo que ambos intercambian conductas cobesivas. No es fácil reconocer al macho que realmente dirige este movimiento

tipo» se produce un continuo proceso de ajuste mediante presión selectiva. Las señales evolucionan a lo largo de la filogenia, según se da la transformación de los distintos patrones motores y se van asentando en el transcurso de las ontogenias para tomar la nueva configuración. El principal problema es la identificación, a partir de esta pauta actual, de todo el complejo proceso de cambio filogenético, ya que se producen modificaciones sobre modificaciones que nos ocultan el origen primitivo: «como muchos caracteres físicos y muchos movimientos instintivos, el desarrollo individual u ontogénesis de una ceremonia ritualizada sigue de un modo general el camino de la filogenia. Pero mirando más de cerca, se observa que la ontogenia no repite la serie de las formas ancestrales, sino la de sus ontogenias» (Lorenz, 1978, p. 193).
Durante el proceso de ritualización, los movimientos se transforman por evolución en mecanismos más eficientes de comunicación. Estos cambios vendrían, de forma general, acompañados de modificaciones morfológicas que aumentarían la visibilidad de las señales, haciendo más patente su función comunicativa (p. e., Wilson, 1980). Si bien el ritual necesita ser perfectamente visto e interpretado por el receptor, está claro que no son $\tan$ importantes las modificaciones morfológicas que se producen en especies de campo abierto, comparadas con las de aquellas especies cuyas condiciones ambientales pudieran restar eficacia a la señal emitida. No digamos, en el mismo sentido, si comparamos especies sociales con especies no sociales. Ya no es tanto la necesidad de magnificar la señal lo que podría ser el camino de la evolución, sino 


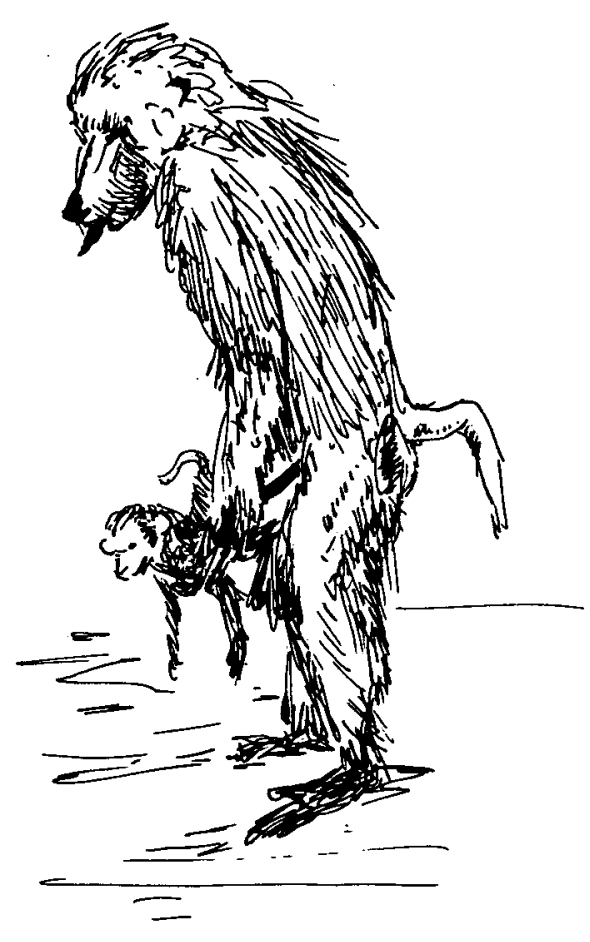

Fig. 6. Algunos machos subadultos fuerzan a la presentación y a la monta a algunos jóvenes. Esta conducta podría estar relacionada con la buisqueda de futuras alianzas entre ambos machos

la necesidad de adecuar, cuantitativa y cualitativamente, estas señales a cada nueva situación para obtener una máxima interpretación del contenido del mensaje en relación con el contexto social.

Así, por ejemplo, se pueden encontrar características sociales básicas que difieren dentro del género Papio. Los babuinos sagrados ( $P$. bamadryas) poseen una estructura social cerrada, forman harenes de un único-macho-líder con sus hembras y jóvenes, constituyendo la unidad social básica en la que se da exclusivamente la jerarquía lineal (3). Los miembros de la sociedad hamadríade realizan gran can- tidad de display agresivo y el macho alfa obliga a sus hembras a seguirle mediante agresión («herding behavior») (p.e., Kummer, 1968a, 1968b y 1970; Kummer et al., 1970; Nagel, 1971 y 1973). Los babuinos de sabana ( $P$. cynocepha. lus, $P$. anubis, $P$. ursinus, etc.) (4) po seen una jerarquía lineal que abarca a todo el conjunto del grupo, el display agresivo no es tan frecuente, los machos forman parejas inestables con hembras en celo y es el grupo la unidad social básica. Los babuinos sagrados y los de sabana difieren, de esta forma, en sus estructuras sociales y en las dinámicas que las mantienen (ver Cuadro 1).

Crook (1970a) ha defendido que, dependiendo de factores externos, los distintos niveles de los distintos taxones convergen en la forma de una estructura social. También Crook (1970c) distingue cinco categorías de grupos, basándose en su tamaño y composición edad-sexo. En un primer lugar sitúa a los grupos de pequeño tamaño, de un único macho y gran territorialidad (Colobus, Presbytis e Hilobates). En el otro extremo coloca a los grupos abiertos con poca estabilidad en su estructura interna $(P a n)$. Kummer (1971) ha sugerido otra clasificación: los grupos con un único macho ( $P$. bamadryas, Erythrocebus patas y Theropitbecus gelada), los grupos multimacho (resto de Papio, Macaca) y las familias monógamas (Hylobates). Jolly (1972), a su vez, los clasifica en nocturnos, arbóreos diurnos y parcialmente terrestres. De cualquier forma, todos los autores han coincidido en reunir, en función de la estructura social, a patas, geladas y hamadríades en una misma categoría, aunque las dinámicas que mantienen sus estructuras sociales sean distintas (Crook, 1966 y 1976; Mason, 1976).

Chance (1967 y com. personal) ha hecho una clasificación con base en la agresividad, dividiendo a las sociedades por la cohesión que mantienen sus miem- 
bros entre sí, mediante lo que ha llamado estructura de la atención (ver también Chance y Larsen, 1976). Chance forma dos grupos: sociedades con cohesión agonística, relacionadas con terrenos abiertos en los que la atención directa es factible (Papio y Macaca) y sociedades con cohesión hedónica, no agresivas y situadas en hábitats con reducida visibilidad que requiere un encadenamiento de la atención entre sus miembros (Pan y Gorilla).

Las diferencias o similaridades entre estos grupos, que se encuentran taxonómicamente próximos, se deberían a la coincidencia o diversidad de sus hábitats y/o a la coincidencia o diversidad de los mecanismos que mantienen cada uno de los modelos de estructura, es decir, a las dinámicas sociales características.

Otra cuestión relacionada con lo anteriormente visto, consiste en la dirección que ha ido tomando la evolución de unas formas a otras de estructura. Para Crook y Gartlan (1966), los grupos con un único macho serían una forma especializada a partir del modelo multimacho. Basan su idea en que las fuentes de alimentación se encuentran más dispersas en los primeros por situarse en escenarios semidesérticos. Este hecho requeriría la especialización de una estructura que asegurase la supervivencia y la reproducción, sobre todo en los períodos de máxima escasez. La formulación contraria, es decir, la formación del modelo multimacho partiendo de los único-macho, tiene su apoyo en que los primates menos evolucionados se caracterizan por vivir en solitario, yendo hembras y machos por separado salvo en la época de cría. La evolución hacia estructuras más permanentes se produciría en dos direcciones: la familia monógama y los harenes. Cualquiera de estos dos modelos podría originar el grupo único-macho estable y la sociedad multimacho aparecería en el último lugar (Eisenberg et al., 1972; Mason, 1976). Otro enfoque que pudiera estar relacionado con este problema, desde un punto de vista sociobio. lógico, puede encontrarse en Trivers (1972 y 1974).

De cualquier forma, según las especies se van separando de la protección de la selva, se van produciendo transformaciones a nivel fisiológico y social en consonancia con el nuevo medio. Los monos patas forman grupos con un único-macholíder y se han especializado como ningún otro primate en la locomoción rápida (Washburg y Hamburg, 1965). Los macacos y babuinos se encuentran dotados de grandes caninos como sistema de defensa contra los depredadores, al mismo tiempo que han adquirido un alto nivel de conducta agonística y desarrollado una ordenación jerárquica elaborada (Hall y DeVore, 1965). Por último, los babuinos de zonas desérticas o semiáridas y los geladas adquieren un sistema de organización social más cerrado que favorece la alimentación y la reproducción en los momentos de máxima escasez (Crook, 1966 y 1970a). Chance (1967), basándose en el artículo de Kummer y Kurt (1963), opina que en la sociedad hamadríade, la atención de las hembras se encuentra restringida a su propio grupo y concretamente sobre su macho-alfa. Aparte de esta atención y por el estricto marco de movimientos que ofrecen las «rocas de dormir", las hembras podrían seguir a su macho en cuanto éste se moviera mínimamente. De todo esto se deduce que las condiciones ecológicas de los babuinos de sabana, en las que se desarrollan sus sistemas de organización, no llevaría a la adquisición de un sistema tan cerrado como el de hamadríade.

Como se ve en los estudios realizados por Stuart y Jeanne Altmann (1970), se podría pensar que entre los cinocéfalos, la sociedad total y el subconjunto reproductor son coincidentes y que la cantidad de información transferida genéticamente entre un gran grupo y otro es muy in. 
ferior a la que se produce como consecuencia del intercambio de machos entre los subgrupos. Si establecemos una comparación con el tipo de sociedad hamadríade, vemos que el conjunto social (tropa) y el deme no coinciden, debido a la subdivisión en harenes donde se da exclusivamente la reproducción. En segundo lugar, su sistema de organización social, al estar basado en elementos agresivos (Kummer et al., 1970) necesitaría de mecanismos especiales para paliar esta agresión o para mantener la atención entre los miembros. En este sentido, la afirmación hecha por Nagel (1973) de que la hibridación se produciría mediante la integración, en el Awash Valley, de hembras anubis desde sus grupos originales a los de hamadríade o híbridos, con una sola dirección de intercambio genético, ha sido rebatida tecientemente. Sugawara (1979 y com. personal) establece dos nuevas vías de intercambio: la integración de machos anubis solitarios en grupos de hamadríade y al revés, es decir, la integración de machos hamadríade en grupos de anubis, permaneciendo allí y copulando con sus hembras. Desde luego, resulta más difícil asumir la primera vía argumentada por Sugawara, dada la menor capacidad de display agresivo que poseen los anubis y su menor capacidad para amortiguar las posibles agresiones de los machos hamadríade líderes en la competencia por sus hembras. No obstante queda por resolver la viabilidad de cualquier conclusión a tenor de los datos sobre intercambio genético que pudiera influir en la estructura social de estas especies. Lo que sí parece evidente es que, en cualquiera de los casos, la dilatada emisión de estímulos agresivos sin ninguna inhibición, podría llevar a un aumento desmesurado de la agresividad que resultara inadaptativa para la supervivencia del grupo (Peláez, 1982).

Es, pues, razonable pensar que los movimientos de saludo no se realicen de la misma manera, sino que las distintas especies de babuinos pueden tener sus formas peculiares de saludar en consonancia con que las diferentes relaciones sociales sean más o menos agresivas. Debe existir una estrecha unión entre la agresividad y la necesidad de amortiguarla: el papel de los movimientos de saludo sería la inhibición o reducción de cualquier ataque intraespecífico, máxime cuando la huida resulte poco ventajosa para el conjunto del grupo. El apaciguamiento reduciría stress en el individuo sumiso, ya que el apartarse minimiza los estímulos aterradores que el dominante le impone. $\mathrm{Al}$ tiempo, la tendencia a la huida se reduce y el animal permanecerá en el grupo (Chance, 1962; Manning, 1972).

Si en la sociedad hamadríade, como se ha visto, aparecen más elementos agresivos, al mismo tiempo que es más dependiente de los recursos alimenticios por las peculiaridades del hábitat, cabe esperar el establecimiento de nuevas formas de interacción tendentes a amortiguar con efectividad un "exceso" de agresividad contradictoria con su propia forma de estructura. Los movimientos de saludo específicos del hamadríade tendrían, por tanto, una doble vertiente: si la mayor agresividad repercutiera, como cabría esperar, en las relaciones entre los individuos, éstos tenderían a dispersarse en un hábitat que no favorece tal dispersión. Es posible que, en principio, la mayor agresividad del macho fuese útil para mantener la cohesión de su harén, pero esa misma agresividad repercutiría negativamente en el mantenimiento de los grupos. Por tanto, según se diferenciase la estructura social, necesitaría de mecanismos específicos que la mantuviesen, sin ningún tipo de prioridad de aparición. La estructura y los mecanismos que la mantienen poseerían una influencia y se darían en el tiempo con el objetivo de paliar los cambios ambientales. 
Quizá, los movimientos específicos de hamadríade se darían exclusivamente entre los machos líderes de cada harén o entre aquellos machos que compiten por sus hembras. Este argumento se ve reforzado por el hecho de que cuando la composición del harén del macho sagrado de la colonia ha variado, al perder la mayoría de sus hembras, también ha disminuido (si no desaparecido) la cantidad de movimientos de saludo en Círculo, Semicírculo y Cara a cara que mantenía con el otro líder de la colonia.

Anteriormente, al hablar del apaciguamiento del individuo sumiso, se establecía un nuevo punto de vista relacionado con la jerarquía. De una forma general, se ha pensado que la presentación y la monta entre machos provenía, por derivación, de la monta sexual. De aquí se dedujo que entre los participantes podría haber una relación dominante-sumiso en la que el macho que se presenta o es montado tuviese una posición jerárquica inferior, por similitud con el «papel» de la hembra en la monta sexual.

Sugawara (1979) ha establecido tres categorías que clasifican dicha relación. La primera sería el caso en el que el macho dominante dirige el saludo. En segundo lugar, el sumiso sería el director $y$, por último, la situación en la que la posición jerárquica de los participantes fuera ambigua. Solamente cuando en la realización de los movimientos aparece una palpación mutua de los genitales, no parece haber coincidencia, según Sugawara, entre el grado de dominancia y el director del saludo. El dominante sería el director en el saludo de Monta y el subordinado lo sería del saludo de Presentación. No obstante, no es fácil observar un saludo de Monta sin una anterior presentación: bien porque el macho supuestamente dominante solicite la presentación, pudiendo o no montar a continuación, bien porque sea el subordinado el que se presente pudiendo $o$ no ser montado por el dominante. Seguramente, la posición de iniciador o receptor en los movimientos de saludo es más una cuestión dependiente del contexto que de la jerarquía, aunque no pueda negarse esta posibilidad. De cualquier forma, el concepto de dominancia y sumisión es muy debatido en la literatura y los roles individuales (distintos por muchas circunstancias) pudieran tener gran importancia en la direccionalidad de los movimientos y en la participación de los machos.

En sus estudios sobre geladas, Kummer (1974 y 1975) opina que la presentación no es exclusivamente una conducta de sumisión, sino reductora de las interacciones agonísticas, siendo utilizada en ambas direcciones de la escala de dominancia. Para Kummer es necesaria una lucha antes de una presentación de un macho beta a un alfa (tratado como rol). También mantenía un paralelismo entre la presentación y la notificación («notifying behavior», Kummer (1968a)) hecha por un hamadríade líder a otro líder de un harén vecino ante un inminente abandono del lugar. Es posible que fuese necesario un conflicto para alcanzar una posición social antes de establecer los saludos de Monta y Presentación, es decir, que el saludo se produciría con la condición de que hubiese una relación ya establecida. El macho dominante podría presentarse al subordinado en lugar de su propia hembra, cuando apareciese algún elemento competitivo sexual entre ambos machos (el poseedor y el rival) (Kummer, 1975). Según esto, se podría establecer una relación entre la presentación y la idea de posesión en un sentido amplio. Los animales poseedores, de un objeto, de alimento o de un congénere, saludarían a los rivales por esta posesión y no al revés (Kummer, 1973; Kummer et al., 1978). Esta idea parte de la inhibición observada en los machos hamadríade (incluso en los dominantes) a usurpar los objetos poseídos por otros 


\section{Estudios}

machos (ver también Kummer et al., 1974). La consecuencia podría ser que la presentación notificaría una cierta relajación del poseedor hacia el rival; si el poseedor actuara de forma más precavida, siempre según Kummer, el rival tendría la señal evidente de la inseguridad producida por la posesión de ese objeto (o hembra). Los actos de rivalidad por una competencia sexual serían más frecuentes entre aquellos machos que hubieran permanecido juntos hasta el momento de la «toma de sus hembras».

En el mismo sentido, pero desde otra perspectiva, se podría aducir que el ascenso en la jerarquía (status o rol) y/o en la competición por las hembras, se ven acompañados por una continua búsqueda de alianzas. Crook (1970a) afirma que dichas alianzas pudieran establecerse utilizando a machos más jóvenes mediante actos de salutación. No existiría, por tanto, una relación estricta entre el acto de presentarse y la intención de hacerlo. El macho que lleva la iniciativa podría, como decía anteriormente, invitar (en ocasiones forzar) a la presentación y a la monta a los machos más jóvenes como sello de colaboración y alianza en el futuro. De hecho, se observa que los machos subadultos obligan materialmente a presentarse a jóvenes de dos o tres meses (incluso menos), atrayéndolos hacia sí y montándolos a continuación (Fig. 6). No es difícil ver cómo se producen maniobras de apoyo en determinados conflictos entre dos machos, en los que un tercero decanta hacia uno $u$ otro lado la resolución de los mismos. Esta resolución favorable de las competencias, con el apoyo de otro macho, podría venir como consecuencia de las alianzas prefiguradas en un pasado quizá lejano. Resulta, por tanto, evidente que la realización temprana que asegure esas futuras alianzas, daría una ventaja al macho con mayor capacidad de interacción. El saludo se enmarcaría, desde este punto de vista, dentro de las relaciones amistosas que serían más fáciles de establecer según los escalones sociales a los que pertenezca el individuo: familia, edad, harén o simplemente preferencia. Los machos irían organizando sus estrategias con vistas a ocupar un determinado nicho en el grupo (Colmenares a y b, en prensa). Si como dicen Kummer et al. (1978), los rivales más peligrosos de un líder de harén eran los jóvenes con los que más íntimamente había estado asociado, parece probable que sus estrategias hubiesen ido cambiando para llegar a alcanzar los lugares más apetecibles dentro del grupo. Los machos que van ocupando estos distintos nichos sociales a lo largo de sus vidas, necesitarían (para ocuparlos y/o mantenerlos), sus propios mecanismos de interacción. Dentro de esta variabilidad de estrategias se situarían los diferentes tipos de conductas, entre las que cabría incluir los movimientos de saludo. De momento y con respecto a esta idea (a la espera de nuevos datos que nos proporcionen mayor información), sería suficiente decir que los movimientos de saludo no tienen por qué tener una función determinada (mucho menos exclusiva), sino que con una base inhibidora agonística, formarían parte del repertorio de conductas relacionadas con el ascenso o mantenimiento de una determinada influencia en el grupo. Esto explicaría que hubiese movimientos de saludo característicos de determinadas posiciones sociales que pudieran no darse entre aquellos individuos que no hubieran tenido oportunidad de alcanzarlas y, explicaría quizá, la existencia de un repertorio distinto de movimientos de saludo entre especies que, aún estando muy cerca en la escala taxonómica, poseen distintas estructuras sociales. Las diferencias en el repertorio se deberían, en este último caso, a que en una y otra especie no existen las mismas posiciones sociales a ocupar por los individuos. 


\section{CONCLUSIONES}

A lo largo de este artículo se ha hecho, en primer lugar, una exposición de posturas teóricas en torno a la estructura social (ver Introducción). En segundo lugar, se ha planteado la discusión con la intención de encontrar posibles implicaciones mutuas entre la estructura social y la conducta misma. Para ello se ha estudiado una categoría concreta de conducta que, por ser muy elaborada, se consideró de especial interés en la coordinación de los grupos sociales: los movimientos de saludo. Se han tratado las maniobras de salutación a un nivel conceptual (como actos ritualizados que son), introduciéndose como un caso concreto en el género Papio. Las conclusiones a las que se pretende llegar no son sino un avance de los estudios llevados a cabo en la actualidad. Estudios que tienen como punto de partida el interrogante creado por el hecho de que dos especies taxonómicamente muy próximas difieran en sus estructuras y en sus conductas.

En primer lugar, considerando el punto donde la estructura social está directamente influida por los condicionamientos externos, las variaciones que se produjesen vendrían acompañadas necesariamente por variaciones en los repertorios sociales. Es decir, las estructuras y los mecanismos que las mantienen se producirían sin ninguna prioridad en su aparición. Esto explicaría que especies con una determinada estructura tuviesen un repertorio de conductas (a nivel cuantitativo y cualitativo) en consonancia con su hábitat, independientemente de su proximidad taxonómica, al estar sometidas a distintas presiones ambientales.
Por otra parte y a otro nivel, los individuos organizan sus conductas elaborando estrategias que les permitan acceder a los distintos nichos sociales y asegurar su legado genético. En este contexto, los movimientos de saludo formarían parte del repertorio social, adecuado individualmente a las circunstancias para formar alianzas y, en definitiva, modificar el statu quo que le impide dicho acceso. La idiosincrasia juega un papel importante en el cómo y cuándo realizar las conductas.

En el nivel social, a cada unión interindividual, a cada clase de edad o sexo le corresponde circunstancialmente su propio repertorio conductual dependiendo del tipo de estructura. El repertorio se manifestaría de distinta forma entre el individuo que pugna por acceder a la situación apetecible y aquellos que ya la poseen e intentan mantenerla. A cada escalón social le correspondería, en uno u otro sentido, su propio repertorio. Esto explicaría las diferencias direccionales de los movimientos realizados entre dos individuos y también el hecho de que una especie, al tener por su estructura distintos nichos a ocupar, poseyese repertorios acordes a cada uno de ellos. La configuración de la estructura de hamadríade, por su organización en harenes, es una clara muestra de estas diferencias respecto a los nichos que hubiese en la sociedad de cinocéfalos.

$\mathrm{El}$ que una categotía de conducta como los movimientos de saludo posea tanta versatilidad, no es sino un caso más sobre la imposibilidad de adscribir a la conducta una función concreta, máxime en ámbitos tan elevados de la escala evolutiva como son los primates. 


\section{Notas}

(1) El criterio de apariencia del híbrido o índice de hibridación empleado se basa en el artículo de Nagel (1973), referido a los aspectos comparativos entre grupos de papiones sagrados ( $P$. hamadryas), anubis ( $P$. anubis) e híbridos de ambas especies en Etiopía. Nagel establece ocho elementos de comparación para obtener una clasificación morfológica. De esta forma, el índice vendría dado al asignar valor 0 para apariencia de sagrado, valor 1 para apariencia intermedia y valor 2 para apariencia de anubis (en nuestro caso de cinocéfalo) para cada uno de los elementos de comparación. Posteriormente, Shotake et al. (1977) afirma que los criterios de Nagel coinciden con sus propios resultados a partir de muestras de sangre analizadas por electroforesis. El macho híbrido de nuestra colonia tendría valor 4 para el total de los elementos de comparación, es decir, una clara apariencia de sagrado.

(2) En el saludo en semicírculo, los machos giran entre sí tan sólo $180^{\circ}$. En principio podría parecer una simple diferencia en intensidad con relación al saludo en círculo (los machos giraban $360^{\circ}$ ). Sin descartar esta posibilidad y a la espera de posteriores análisis del contexto, se seguirán considerando como dos saludos distintos a tenor de su diferente configuración (Peláez, 1982).

(3) El concepto de jerarquía, de una forma general, ha sido objeto de arduas polémicas en los últimos años. Una revisión de las distintas opiniones, aún brevemente, nos llevaría a apartarnos de la idea de este trabajo. No obstante, como se deducirá a lo largo de la discusión, el tema tiene gran interés para la dilucidación de las causas y/o funciones de los movimientos de saludo.

(4) De una forma general, al hablar de babuinos de roca o desierto, nos referimos a los papiones sagrados ( $P$. hamadryas) y a los geladas (Tberopitbecus gelada). Aunque este último no se incluyó dentro de Papio, al establecerse un nuevo concepto de Tribu, se le ha considerado normalmente como un babuino más. Ambos se localizan en las regiones áridas del Este de Africa (Etiopía, Somalia, etc.), aunque se encuentran a distintas alturas rocosas. Los babuinos de sabana abarcan un mayor número de especies: papiones amarillos ( $P$. cynocephalus) localizados en toda Africa central, papiones de Guinea ( $P$. papio), papión oliva ( $P$. anubis) con una zona de hibridación con sagrados a lo largo del río Awash y papión chacma ( $P$. ursinus) en Africa del Sur. Otro grupo, los babuinos de bosque se separaron de Papio para «evitar confusiones de clasificacións: los mandriles (Mandrillus sphinx) y los driles (M. leucophaeus), a los que muchos autores tienden a considerar como auténticos babuinos. Los grupos se formaron atendiendo a criterios paleontológicos, etológicos y ecológicos, aunque, por supuesto, no resulten perfectamente satisfactorios.

\section{Resumen}

Independientemente de la proximidad taxonómica, dentro del género Papio existen distintas formas de estructura social. Al mismo tiempo se encuentran diferencias cuantitativas y cualitativas en los repertorios de conducta de las dos especies estudiadas ( $P$. bamadryas y $P$. cynocephalus), concretamente en los movimientos de salutación.

Se buscó una relación entre dichas estructuras sociales y los respectivos movimientos de saludo que aparecían como característicos de cada especie. La estructura social podría modificarse rápidamente por las presiones ambientales, por lo que serían necesarios nuevos repertorios conductuales en consonancia con el cambio y al mismo tiempo que éste.

Al menos en niveles tan altos de la escala evolutiva, los individuos son capaces de organizar sus conductas según su posición respecto al conjunto del grupo y adecuarlas para acceder a los distintos nichos sociales. Por tanto, no es posible adscribir a la conducta una función exclusiva, sino que dependería de la idiosincrasia individual y de los distintos escalones sociales característicos de una determinada estructura social. 


\section{Summary}

Different kinds of social structure exist in baboons (Papio), with independence of their taxonomic proximity. At the same time, there are quantitative and qualitative differences in the behavioural repertoires of the studied species ( $P$. bamadryas y $P$. cynocephalus), refered to greeting movements concretely.

The relation between these social structure and their respective greeting movements, which appeared as species specifics, was investigated. The social structure would be modificated by the environmental pressures quickly and would need other behavioural repertoires related to these changes and at the same time of them.

At least, at the so high levels in the evolution, the individuals are able to organize their behaviours according to their position in the group. These behaviours can be accomodated to accede to the different social niches. Therefore, it is not possible to adscribe to behaviour any exclusive function, but it would depend of the individual idiosyncrasy and the different characteristic social steps of a determinate social structure.

\section{Resumé}

Indépendamment de la proximité taxonomique, ils existent des formes diverses d'structure sociale parmi les babouins (Papio). Au même temps, on se trouvent des différences quantitatives et qualitatives dans les répertoires de la conduite des espèces étudiées ( $P$. bamadryas et $P$. cynocephalus), particulièrement référé aux mouvements de salutation.

On a cherché une relation entre les structures sociales et les respectifs mouvements de salutatiòn, lesquels se présentaient comme charactéristiques de chaque espèce. L'structure sociale pourrait être modifiée rapidement par les pressions de l'environnement et pour cela il serait nécessaire des nouveaux répertoires de la conduite en consonance avec le change et au même temps que celui-ci.

Du moins, aux niveaux si hauts de l'évolution, les individus ont été capables d'organiser ses conduites selon leur position dans le groupe et les apropprier pour accéder aux différents niches socials. Par conséquent, il n'est pas possible circonscrive la conduite à une fonction exclusive; la conduite dépendra de l'idiosyncrasie individuelle et des différents degrés socials d'une determinée structure sociale.

\section{Referencias}

AltmanN, J.: «Observational study of behavior: sampling methods», Bebaviour, 49: 229-267, 1974.

Altmann, S. A., \& Altman,, J.: Baboon Ecology: African Field Research, Univ. of Chicago Press, Chicago, 1970.

ANTHONEY, T. R.: «Evolution of social structure in baboons (Papio SPP.): detailed analysis of social structure in a captive group of guinea baboons (Papio papio) and a comparative review and analysis of social structure in all species of genus», Unpublished $\mathrm{Ph} . \mathrm{D}$. thesis, Univ. of Chicago Illinois, 1975.

Chance, M. R. A.: "An interpretation of some agonistic postures; the role of 'cut-off' acts and postures», Symp. Zool. Soc. Lond., 8: 71-89, 1962.

ChANCE, M. R. A.: «Attention structure as the basis of primate rank orders», Man, 2: 503-518, 1967.

CaAnce, M. R. A., \& LARSEN, R. R. eds.: The Social Structure of Attention, John Wiley and Sons, Londres, 1976. 
ConEN, J. E.: «Natural primate troops and a stochastic population model», American Naturalist, 103 (933): 455-477, 1969.

COLMENAREs, R.: «Structure sociale d'une bande de loups iberiques (Canis lupus signatus) en captivité: strategies et niches sociaux», Biol. Behav. (en prensa).

Colmenares, R.: "Visión ecoetológica de las estrategias y nichos sociales en una banda de lobos ibéricos (Canis lupus signatus) en cautividad», Proceedings of the XV Congress of the International Union of Game Biologist (en prensa).

CROox, J. H.: «Gelada baboon herd structure and movement, a comparative report», Symp. Zool. Soc. Lond., 18: 237-258, 1966.

Croor, J. H.: «Social organization and the environment: aspects of contemporary social ethology", Anim. Bebav., 18: 197-209, 1970 a.

CROor, J. H.: «Social behaviour and ethology». En: J. H. Crook, ed., Social Bebaviour in Birds and Mammals, pp.: xi-xxi, Academic Press, Londres, $1970 b$.

Crook, J. H.: «The socioecology of ptimates». En: J. H. Crook, ed.: Social bebaviour in Birds and Mammals, pp.: 103-106, Academic Press, Londres, 1970c.

CROOR, J. H.: «Problems of inference in the comparison of animal and human social organization». En: M. von Cranach, ed.: Methods of Inference from Animals to Man., pp.: 238268, Mouton, París, 1976.

CRoor, J. H., \& Gartlan, J. S.: «Evolution of primate societies», Nature (Londres), 210: 1200-3, 1966.

Eisenberg, J. F.; MucKenhirn, N. A., \& Rudran, R.: «The relation between ecology and social structure in primates», Science, 176: 863-874, 1972.

GARTLAN, J. S.: «Influences of phylogeny and ecology on variations in the group organization of primates», Proceed. 4th Int. Congr. Primat., Vol. 1: Precultural Primate Bebavior, 1972, pp. 88-101, Karger, Basel, 1973.

HALL, K. R. L.: «Aggression in monkey and ape societies». En: P. C., Jay, ed.: Primates: Studies in Adaptation and Variability, pp. 149-161, Holt, Rinehart \& Winston, Nueva York, 1968.

Hall, K. R. L. \& DeVore, L.: «Baboon social behavior». En: I. DeVore, ed.: Primate Bebavior, pp. 53-110, Holt, Rinehart \& Winston, Nueva York, 1965.

Hausfater, G.: Dominance and Reproduction in Baboons (Papio cynocepbalus). A Quantitative Analysis. En: Contributions to Primatology, Vol. 7, Karger, Basel, 1975.

HINDE, R. A.: «Interactions, Relationships and Social Structure in Non-Hman Primates». En: S. Kondo, M. Kawai, A. Ehara \& S. Kawamura, eds.: Contemporary Primatology, pp. 1324, Proceedings from the Symposia of the 5th Congress of the International Primatological Society, Nagoya, 1974, Japan Science Press, 1975.

HINDE, R. A.: «Bases Biológicas de la Conducta Social Humana», Siglo XXI, eds., 1977.

JoLly, A.: «The Evolution of Primate Behavior», MacMillan, Nueva York, 1972.

Kummer, H.: Social Organization of Hamadryas Baboons, Bibl. Primatol. N.o 6, Chicago, Univ. of Chicago Press and Basel, Karger, 1968a.

Kummer, H.: «Two variations in the social organization of baboons». En: P. C. Jay, ed.: Primates: Studies in Adaptation and Variability, pp. 293-312, Holt, Rinehart \& Winston, N. York, 19686.

Kummer, H.: «Behavioral characters in primate taxonomy». En: J. R. Napier \& P. H. Napier, eds.: Old World Monkeys: Evolution, Sistematics and Behaviour, pp. 25-36, Academic Press, Londres, 1970.

Kummer, H.: Primate Societies, Aldine, Chicago, 1971.

Kummer, H.: «Dominance versus Possession. An Experiment on Hamadryas Baboons. Proceed», 4th Int. Congr. Primat., 1972, Vol. 1: Precultural Primate Bebavior, pp. 226-231, Karger, Basel, 1973.

Kummer, H.: «Distribution of interindividual distaces in Patas monkeys and Gelada baboons», Folia primat., 21: 153-160, 1974.

Kummer, H.: «Rules of Dyad and Group Formation among Captive Gelada Baboons (Theropithecus gelada)». En: S. Kondo, M. Kawai, A. Ehara \& S. Kawamura, eds.: Contemporary Primatology, pp. 129-159. Proceedings from the Symposie of the 5th Congress of the International Primatological Society, Nagoya 1974, Japan Science Press, 1975.

Kummer, H.; Abegglen, J. J.; Falett, J.; Bachmann, Ch., \& Sigg, H.: «Grooming relationship and object competition among hamadryas baboons», Zoologisches Institüt Universität Zurich, pp. 31-38, 1978.

KuMMER, H.; GOETZ, W., \& ANGST, W.: «Cross-species modification of social behavior in baboons». En: J. R. Napier \& P. H. Napier, eds.: Old Worl Monkeys: Evolution, Systematics and Bebaviour, pp. 351-363, Academic Press, Londres, 1970.

Kummer, H.; GoeTz, W., \& ANGST, W.: "Triadic differentiation: an inhibitory process protecting pair bonds in baboons", Behaviour, 49: 62-87, 1974.

Kummer, H., \& KURT, F.: «Social units of a free-living population of Hamadryas baboons», Folia primat., 1: 4-19, 1963. 
Lorenz, K.: Sobre la Agresión, el Pretendido Mal, 8." ed., Siglo XXI, 1978.

Manning, A.: Introducción a la Conducta Animal, Alianza Universidad, Alianza ed., 1972.

Mason, W. A.: «Primate social behavior: pattern and process». En: R. B. Masterton, et al., eds.: Evolution of Brain and Bebavior in Vertebrates, pp. 425-455, Lawrence Erlbaun Associates, N. Jersey, 1976.

NAGEL, U.: «Social Organization in a Baboon Hybrid Zone», Proc. 3rd Int. Congr. Primat., Zurich 1970, Vol. 3, pp. 48-57, Karger, Basel, 1971.

NAGEL, U.: «A Comparison of Anubis Baboons, Hamadryas Baboons and their Hybrids at a Species Border in Ethiopia», Folia primat., 19: 104-165, 1973.

PELÁEZ, F.: «Greeting Movements among Adult Males in a Colony of Baboons: Papio bamadryas, P. cynocephalus and their Hybrids. Primates», 1982.

Shotake, T.; Nozawa, K., \& Tanabe, Y.: «Blood protein variations in baboons: I. Gene exchange and genetic distance between Papio anubis, Papio bamadryas, and their hybrids», Japan J. Genetics, 52 (3): 223-237, 1977.

SUGAWARA, K.: «Sociological study of a wild group of hybrid baboons between Papio anubis and P. bamadryas in the Awash Valley», Ethiopia. Primates, 20 (1): 21-56, 1979.

Thorpe, W. H.: The Origins and Rise of Etbology, Eeinemann Educational Books, Londres, 1979.

Trivers, R. L.: «Parental investment and sexual selection». En: G. B. Campell, ed., Sexual Selection and the Descent of Man, 1871-1971, pp. 136-179, Aldine, Chicago, 1972.

TrIvers, R. L.: «Parent-offspring conflict». American Zoologist, 14: 249-264, 1974.

W ASHBURN, S. L., \& HAmbURG, D. H.: «The implications of primate research». En: I. DeVore, ed.: Primate Bebavior: Field Studies of Monkeys and Apes, pp. 607-622, Holt, Rinehart and Winston, N. York, 1965.

Wilson, E. O.: Sociobiología. La Nueva Sintesis, Omega eds., 1981. 